\title{
Does interbody cage lordosis impact actual segmental lordosis achieved in minimally invasive lumbar spine fusion?
}

\author{
Francis C. Lovecchio, MD, ${ }^{1}$ Avani S. Vaishnav, MBBS, ${ }^{1}$ Michael E. Steinhaus, MD, ${ }^{1}$ \\ Yahya A. Othman, MD, ${ }^{2}$ Catherine Himo Gang, MPH, ${ }^{1}$ Sravisht lyer, MD,, 13 \\ Steven J. McAnany, MD, ${ }^{1,3}$ Todd J. Albert, MD, ${ }^{1,3}$ and Sheeraz A. Qureshi, MD, MBA, \\ ${ }^{1}$ Hospital for Special Surgery, New York, New York; ${ }^{2}$ Weill Cornell Medicine-Qatar, Alsad, Doha, Qatar; and ${ }^{3}$ Weill Cornell \\ Medical College, New York, New York
}

\begin{abstract}
OBJECTIVE In an effort to prevent loss of segmental lordosis (SL) with minimally invasive interbody fusions, manufacturers have increased the amount of lordosis that is built into interbody cages. However, the relationship between cage lordotic angle and actual SL achieved intraoperatively remains unclear. The purpose of this study was to determine if the lordotic angle manufactured into an interbody cage impacts the change in SL during minimally invasive surgery (MIS) for lumbar interbody fusion (LIF) done for degenerative pathology.

METHODS The authors performed a retrospective review of a single-surgeon database of adult patients who underwent primary LIF between April 2017 and December 2018. Procedures were performed for 1-2-level lumbar degenerative disease using contemporary MIS techniques, including transforaminal LIF (TLIF), lateral LIF (LLIF), and anterior LIF (ALIF). Surgical levels were classified on lateral radiographs based on the cage lordotic angle $\left(6^{\circ}-8^{\circ}, 10^{\circ}-12^{\circ}\right.$, and $15^{\circ}-20^{\circ}$ ) and the position of the cage in the disc space (anterior vs posterior). Change in SL was the primary outcome of interest. Subgroup analyses of the cage lordotic angle within each surgical approach were also conducted.
\end{abstract}

RESULTS A total of 116 surgical levels in 98 patients were included. Surgical approaches included TLIF (56.1\%), LLIF $(32.7 \%)$, and ALIF $(11.2 \%)$. There were no differences in SL gained by cage lordotic angle $\left(2.7^{\circ} \mathrm{SL}\right.$ gain with $6^{\circ}-8^{\circ} \mathrm{cag}$ es, $1.6^{\circ}$ with $10^{\circ}-12^{\circ}$ cages, and $3.4^{\circ}$ with $15^{\circ}-20^{\circ}$ cages, $p=0.581$ ). Subgroup analysis of LLIF showed increased $\mathrm{SL}$ with $15^{\circ}$ cages only $(p=0.002)$. The change in SL was highest after ALIF (average increase $9.8^{\circ}$ in SL vs $1.8^{\circ}$ in TLIF vs $1.8^{\circ}$ in LLIF, $\left.p<0.001\right)$. Anterior position of the cage in the disc space was also associated with a significantly greater gain in $S L\left(4.2^{\circ} \mathrm{vs}-0.3^{\circ}, p=0.001\right)$, and was the only factor independently correlated with $S L$ gain $(p=0.016)$.

CONCLUSIONS Compared with cage lordotic angle, cage position and approach play larger roles in the generation of $S L$ in 1-2-level MIS for lumbar degenerative disease.

https://thejns.org/doi/abs/10.3171/2020.6.FOCUS20393

KEYWORDS minimally invasive spine surgery; interbody cage; lumbar lordosis; cage lordotic angle; actual segmental lordosis

$\mathrm{T}$ HE maintenance or restoration of sagittal alignment during lumbar fusion surgery is critical to achieve optimal mechanical and patient-reported outcomes. This relationship has been demonstrated regardless of the indication for surgery or the surgical approach. ${ }^{1,2}$ Specifically, in minimally invasive surgery (MIS) techniques performed for degenerative lumbar conditions, the interbody cage being used is often the sole driver of postoperative lordosis. ${ }^{3,4}$ Despite the reported advantages of interbody devices in MIS fusion surgery (increased surface area for fusion, restoration of disc height, indirect foraminal decompression), MIS interbody fusions have been associated with a "flattening effect" in the lumbar spine, putting patients at risk for suboptimal postoperative alignment and poor outcomes. ${ }^{5,6}$ To overcome such deficiencies, MIS surgeons will often use an interbody cage that has been manufactured with a greater amount of "built-in" lordosis. Although the use of a lordotic cage theoretically increases

ABBREVIATIONS ALIF = anterior lumbar interbody fusion; ALL = anterior longitudinal ligament; LIF = lumbar interbody fusion; LLIF = lateral lumbar interbody fusion; MIS = minimally invasive surgery; $\mathrm{PI}=$ pelvic incidence; $\mathrm{PT}=$ pelvic tilt; $\mathrm{SL}=$ segmental lordosis; $\mathrm{SS}=$ sacral slope; TLIF = transforaminal lumbar interbody fusion.

SUBMITTED May 7, 2020. ACCEPTED June 23, 2020.

INCLUDE WHEN CITING DOI: 10.3171/2020.6.FOCUS20393. 
segmental lordosis (SL) through differential distraction of the disc space, it is unclear whether greater cage lordosis actually results in achievement of greater SL in MIS interbody fusions being performed for degenerative lumbar conditions.?

A key difference between MIS and open or hybrid approaches relates to resection of the posterior elements. ${ }^{8}$ MIS techniques being utilized to treat degenerative lumbar conditions focus on minimal bony and ligamentous resection for insertion of the interbody cage. While the maintenance of these structures may be associated with reduced postoperative pain,, 10 it likely restricts the amount of lordosis that can be generated at the operative level., ${ }^{711}$ The combined impact of the surgical approach, cage position, and built-in cage lordotic angle on the amount of postoperative SL achieved remains unclear. ${ }^{12,13}$ The purpose of this study was to determine if the built-in lordotic angle of an interbody cage impacted the actual change in SL achieved with MIS lumbar interbody fusion (LIF) techniques. To our knowledge, our investigation is the largest series of MIS procedures examining the impact of cage lordotic angle on postoperative SL.

\section{Methods}

\section{Patient Sample}

A retrospective review was performed of a singlesurgeon database of adult patients (age 18-80 years) who underwent primary instrumented LIF between April 2017 and December 2018 for degenerative lumbar conditions. ${ }^{14}$ Procedures were performed using contemporary MIS techniques, including transforaminal LIF (TLIF), lateral LIF (LLIF), and anterior LIF (ALIF) approaches. TLIF was performed through a tubular retractor with unilateral facetectomy and placement of percutaneous pedicle screws. ${ }^{15-20}$ LLIF was performed through a tubular retractor without resection of the anterior longitudinal ligament (ALL), with subsequent placement of percutaneous pedicle screws when needed. ALIF was performed through a retroperitoneal approach with the assistance of an access surgeon. Stand-alone cages with inferior and superior endplate screws were utilized, and posterior pedicle screws were not placed. Surgical indications included degenerative disc disease and isthmic or degenerative spondylolisthesis (Meyerding grade 1 or 2 only). For 2-level cases, the same approach was utilized for both levels. Cage heights were chosen by attempting to attain the same height as the disc above the surgical level, with adjustments made intraoperatively depending on the difficulty of cage insertion. Generally, the maximum available cage lordotic angle was chosen, provided that the cage trialing was acceptable and did not appear to risk endplate violation. Notably, deformity corrections were excluded from this series (given that ALL resection is often needed to recreate lost lordosis). Other exclusion criteria were as follows: zero-degree cage, fusions $>2$ levels, additional open posterior approach, or surgical diagnosis of fracture or tumor.

\section{Clinical Data Collection}

The primary outcome of this study was the change in index-level SL. Patient medical records were reviewed to retrieve demographic and surgical information, including age, sex, BMI, surgical approach, index level, and the manufacturer-reported lordotic cage angle. Data were collected and managed using REDCap (Research Electronic Data Capture) and supported by the following grant: CTSC GRANT UL1 TR002384. REDCap is a secure, Health Insurance Portability and Accountability Act (HIPAA)compliant web-based software platform designed to support data capture for research studies. ${ }^{21}$

\section{Radiographic Measurements}

Preoperative and first postoperative (2-6 weeks after surgery) full-length standing radiographs were assessed for the following parameters: lumbar lordosis (upper endplate of S1 to the upper endplate of L1), pelvic incidence (PI), pelvic tilt (PT), and sacral slope (SS). The primary outcome of interest, index-level SL on first postoperative film, was defined as the angle formed between the upper endplate of the superior vertebra and the lower endplate of the inferior vertebra at the index level of surgery. Cage positioning was also assessed and classified as anterior or posterior based on the position of the cage within the disc space. Specifically, the lateral postoperative radiograph was utilized to bisect the inferior endplate at the index level into anterior and posterior halves. The portion of the endplate that contained the majority of the cage footprint was then utilized to categorize the cage position. Radiographic measurements were conducted by 2 independent investigators who used the previously validated surgical planning software Surgimap. ${ }^{22}$

\section{Categorization of Cages}

Each surgical level was categorized based on the cage lordotic angle as reported by the manufacturer $\left(6^{\circ}-8^{\circ}\right.$, $10^{\circ}-12^{\circ}$, and $15^{\circ}-20^{\circ}$ ), the surgical approach, and the position of the cage (anterior vs posterior). Categorization of expandable cages depended on the approach (TLIF or LLIF only), given the differences in cage design. For TLIF, expandable cages had a set cage lordotic angle of $8^{\circ}$ or $15^{\circ}$, and height was then adjusted until the maximum "tension" was reached. Thus, expandable TLIF cages were classified in the $6^{\circ}-8^{\circ}$ or $15^{\circ}-20^{\circ}$ cohorts. For LLIF, expandable cages varied in both height and lordotic angle (initially $3^{\circ}$, expandable to $15^{\circ}$ ). In the few instances that an expandable LLIF was used, the cages were maximally expanded and thus categorized into the $15^{\circ}-20^{\circ}$ cohort.

\section{Statistical Analysis}

Demographic characteristics, surgical factors, and radiographic parameters were compared between cohorts. A subgroup analysis of the cage lordotic configuration within each surgical approach category was also conducted. Continuous variables were compared using ANOVA/Student t-test as appropriate, while categorical variables were compared using chi-square tests. When assumptions for ANOVA were not met, a Welch ANOVA was used. The Tukey test was used for post hoc pairwise comparisons, and type I error rates were adjusted using Bonferroni corrections. Multivariate linear regression was performed to 
TABLE 1. Baseline characteristics of the total study population

\begin{tabular}{|c|c|}
\hline Characteristic & Values \\
\hline Age, yrs & $57.8 \pm 13.1$ \\
\hline \multicolumn{2}{|l|}{ Sex } \\
\hline Male & $53(54.1 \%)$ \\
\hline Female & $45(45.9 \%)$ \\
\hline $\mathrm{BMI}, \mathrm{kg} / \mathrm{m}^{2}$ & $27.4 \pm 4.9$ \\
\hline \multicolumn{2}{|l|}{ Index level* } \\
\hline L2-3 & $6(5.2 \%)$ \\
\hline L3-4 & $25(21.6 \%)$ \\
\hline L4-5 & $51(44.0 \%)$ \\
\hline L5-S1 & $34(29.3 \%)$ \\
\hline \multicolumn{2}{|l|}{ No. of levels } \\
\hline 1 & $80(81.6 \%)$ \\
\hline 2 & $18(18.4 \%)$ \\
\hline \multicolumn{2}{|c|}{ Lordotic cage angle* } \\
\hline $6^{\circ}$ & $5(4.3 \%)$ \\
\hline $8^{\circ}$ & $37(31.9 \%)$ \\
\hline $10^{\circ}$ & $8(6.9 \%)$ \\
\hline $12^{\circ}$ & $9(7.8 \%)$ \\
\hline $15^{\circ}$ & $55(47.4 \%)$ \\
\hline $20^{\circ}$ & $2(1.7 \%)$ \\
\hline \multicolumn{2}{|l|}{ Position of cage ${ }^{*}$} \\
\hline Anterior & $83(71.6 \%)$ \\
\hline Posterior & $33(28.4 \%)$ \\
\hline \multicolumn{2}{|l|}{ Surgical approach } \\
\hline ALIF & $11(11.2 \%)$ \\
\hline LLIF & $32(32.7 \%)$ \\
\hline TLIF & $55(56.1 \%)$ \\
\hline
\end{tabular}

Values are presented as number of patients (\%) unless otherwise indicated. Mean values are presented \pm SD

* Values presented as number of operative levels (\%).

identify independent correlates with the primary outcome of interest (change in SL). Agreement between the 2 investigators carrying out the measurements was assessed using the intraclass correlation coefficient. A type I error rate of $p<0.05$ was considered significant. Statistical analyses were performed using SPSS version 22 (IBM).

\section{Results}

\section{Patient Sample}

Based on the sample criteria, 130 patients were retrieved from the database and 32 were excluded, leaving 98 patients (116 surgical levels) available for analysis. The study cohort included mostly middle-aged patients (mean $57.8 \pm 13.1$ years old), with a healthy to overweight BMI (mean $27.4 \pm 4.9 \mathrm{~kg} / \mathrm{m}^{2}$ ), and approximately split by sex (54.1\% male, $45.9 \%$ female) (Table 1). The most common operative level was L4-5 (44.0\%), and the most frequently utilized cage had a cage lordotic angle of $15^{\circ}(47.4 \%)$. Most cases were single level (81.6\% 1 level, $18.4 \% 2$ levels). Expandable cages were utilized in $84 \%$ of TLIF, $8 \%$
TABLE 2. Types of cages utilized at each operative level, categorized by approach and cage lordotic angle

\begin{tabular}{lccc}
\hline & TLIF* $^{*}(n=64)$ & $\operatorname{ALIF}(n=12)$ & $\operatorname{LLIF}^{*}(n=40)$ \\
\hline $6^{\circ}-8^{\circ}$ & & & \\
\hline Static & 5 & 6 & 12 \\
\hline Expandable & 17 & 0 & 0 \\
\hline $10^{\circ}-12^{\circ}$ & & & \\
\hline Static & 5 & 4 & 10 \\
\hline Expandable & 0 & 0 & 0 \\
\hline $15^{\circ}-20^{\circ}$ & & & 15 \\
\hline Static & 0 & 2 & 3 \\
\hline Expandable & 37 & 0 &
\end{tabular}

Values are presented as number of cages. Expandable TLIF cages had a set cage lordotic angle of $8^{\circ}$ or $15^{\circ}$, expandable LLIF cages were initially $3^{\circ}$ and expanded to $15^{\circ}$ (maximum) for all 3 surgical levels.

${ }^{*}$ Maximum $15^{\circ}$ cage lordotic angle.

of LLIF, and 0\% ALIF (Table 2). There were no differences in pre- and postoperative PT and SS, and LL was maintained (mean $49.4 \pm 13.7$ vs $49.2 \pm 13.0, \mathrm{p}=0.695$ ). Interrater reliability between the 2 investigators achieved an intraclass correlation coefficient of 0.73 , indicative of moderate to good agreement.

\section{Comparison by Surgical Approach}

Surgical approaches included TLIF (56.1\%), LLIF (32.7\%), and ALIF (11.2\%) (Fig. 1). Patients in the TLIF cohort had the highest absolute preoperative LL and SL (Table 3). However, the change in LL was comparable between the 3 cohorts $(p=0.062)$, while the change in SL was highest in the ALIF levels $\left(9.8^{\circ}\right.$ average SL increase for ALIF vs $1.8^{\circ}$ for LLIF vs $1.8^{\circ}$ for TLIF, $p<0.001$; Table 3). Post hoc analyses revealed that the change in SL was different between the ALIF and LLIF groups $(\mathrm{p}=$ $0.002)$ and the ALIF and TLIF groups $(\mathrm{p}<0.001)$, while TLIF and LLIF were comparable $(p=0.832)$.

\section{Comparison by Lordotic Cage Angle}

Cage lordosis was not associated with changes in LL or SL ( $p>0.05$ for all comparisons; Table 4). Subgrouping by surgical approach confirmed this lack of association in the TLIF and ALIF subgroups $(p=0.069$ and 0.514, respectively). However, in the LLIF subgroup there was a significant trend of increased SL with increasing lordotic cage angle (average SL change $-0.93^{\circ}, 6^{\circ}-8^{\circ}$ cages, vs $2.2^{\circ}, 10^{\circ}-12^{\circ}$ cages, vs $4.5^{\circ}, 15^{\circ}$ cages, $\mathrm{p}=0.002$; Table $5)$. Within the LLIF subgroup, post hoc analyses showed that the SL changes in the $6^{\circ}-8^{\circ}$ and $10^{\circ}-12^{\circ}$ cohorts were similar $(\mathrm{p}=0.913)$, while the $15^{\circ}$ cohort had a significantly larger SL increase compared to the other 2 cohorts (vs $6^{\circ}-8^{\circ}, \mathrm{p}=0.003$; vs $10^{\circ}-12^{\circ}, \mathrm{p}=0.040$ ).

\section{Comparison by Cage Position}

Eighty-three (71.6\%) patients had a cage placed in the anterior half of the disc space (Table 1). Compared to a posteriorly positioned cage, an anteriorly positioned cage 

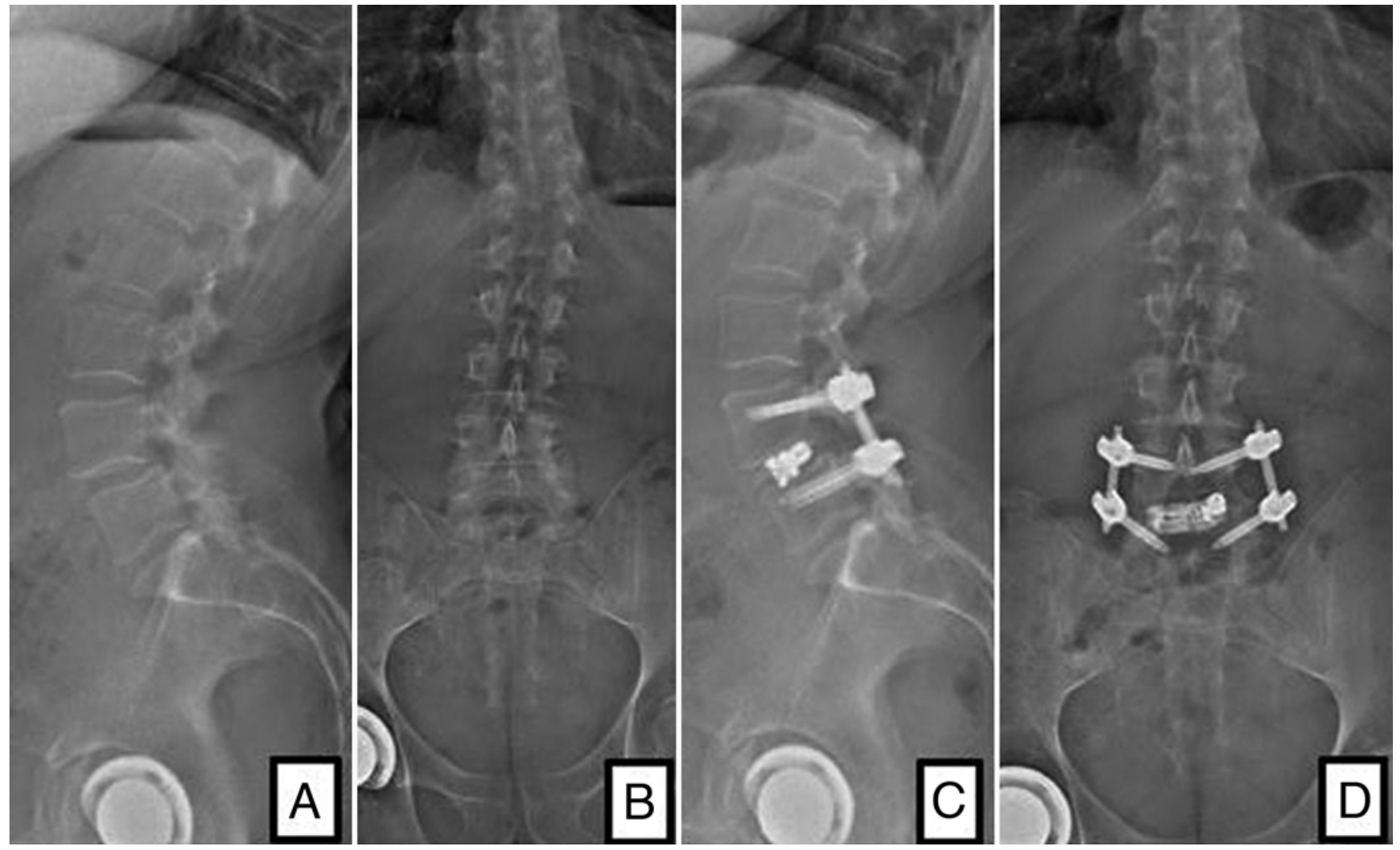

FIG. 1. Images from a 62-year-old man who underwent an L4-5 MIS TLIF using a $15^{\circ}$ expandable cage. A and B: Preoperative radiographs showing an index SL of $22.0^{\circ}$. C and D: Radiographs at 6 weeks postoperatively, with $S L$ measured as $15.5^{\circ}$. Note how the anterior portion of the cage held the disc space open while the vertebral endplates did not approximate the cage lordotic angle.

was associated with a larger increase in SL $\left(4.2^{\circ}\right.$ vs $-0.32^{\circ}$, $\mathrm{p}=0.001$; Table 6 ). Within the subgroup of patients with an anteriorly positioned cage, lordotic cage angle was not associated with SL. Expectedly, ALIF was associated

TABLE 3. Comparison of changes in lordosis by surgical approach

\begin{tabular}{ccccr}
\hline & \multicolumn{4}{c}{ Surgical Approach } \\
\cline { 2 - 5 } & TLIF & LLIF & ALIF & p Value \\
\hline Preop & \multicolumn{5}{c}{} \\
\hline LL & $51.6 \pm 13.9$ & $45.7 \pm 12.6$ & $49.4 \pm 14.3$ & 0.155 \\
\hline SL & $18.5 \pm 6.2$ & $11.85 \pm 7.38$ & $12.3 \pm 4.6$ & $<0.001$ \\
\hline Postop & \multicolumn{5}{c}{} \\
\hline LL & $50.4 \pm 12.3$ & $44.6 \pm 12.8$ & $56.2 \pm 6.8$ & 0.020 \\
\hline SL & $20.3 \pm 6.1$ & $13.69 \pm 6.86$ & $22.1 \pm 5.8$ & $<0.001$ \\
\hline Change & & & & \\
\hline LL & $-1.2 \pm 11.0$ & $-1.7 \pm 9.8$ & $6.8 \pm 11.2$ & 0.062 \\
\hline SL & $1.8 \pm 6.3^{*}$ & $1.8 \pm 3.7^{*}$ & $9.8 \pm 6.9 \dagger$ & $<0.001$ \\
\hline
\end{tabular}

Values are presented as degrees. Mean values are presented \pm SD. The $p$ value reports the type I error rate of the composite test (ANOVA). Pairwise comparisons with Bonferroni corrections are reported for the SL changes only.

* Significantly different compared to ALIF.

† Significantly different compared to LLIF. with a more anteriorly positioned cage (ALIF $100 \%$ vs TLIF $75 \%$ vs LLIF $57.5 \%, \mathrm{p}=0.011$ ).

\section{Independent Correlates With Increased SL}

A linear regression model was generated with change in SL as the outcome of interest. Covariates included surgical approach, interbody implant height (maximum height, measured in $\mathrm{mm}$ ), cage position, and cage lordotic angle. An anteriorly positioned cage was the only independent correlate with increased SL change $(p=0.016)$.

\section{Discussion}

Our retrospective series of 116 minimally invasive

TABLE 4. Comparison of SL by lordotic cage angle

\begin{tabular}{lcccc}
\hline & \multicolumn{4}{c}{ Lordotic Cage Angle } \\
\cline { 2 - 5 } & $\begin{array}{c}6^{\circ}-8^{\circ} \\
(\mathrm{n}=42)\end{array}$ & $\begin{array}{c}10^{\circ}-12^{\circ} \\
(\mathrm{n}=17)\end{array}$ & $\begin{array}{c}15^{\circ}-20^{\circ} \\
(\mathrm{n}=57)\end{array}$ & $\begin{array}{c}\mathrm{p} \\
\text { Value }\end{array}$ \\
\hline Preop SL & $16.2 \pm 7.1$ & $16.0 \pm 8.0$ & $14.0 \pm 8.1$ & 0.319 \\
\hline Postop SL & $18.9 \pm 8.2$ & $17.6 \pm 8.0$ & $17.4 \pm 6.6$ & 0.597 \\
\hline Change in SL & $2.7 \pm 6.3$ & $1.6 \pm 8.0$ & $3.4 \pm 6.6$ & 0.581 \\
\hline
\end{tabular}

Values are presented as degrees. Mean values are presented \pm SD. 
TABLE 5. Comparison of SL change between differing lordotic cage angles, stratified into surgical approach subgroups

\begin{tabular}{|c|c|c|c|c|}
\hline \multirow{2}{*}{$\begin{array}{c}\text { Surgical } \\
\text { Approach }\end{array}$} & \multicolumn{4}{|c|}{ Lordotic Cage Angle } \\
\hline & $6^{\circ}-8^{\circ}$ & $10^{\circ}-12^{\circ}$ & $15^{\circ}-20^{\circ}$ & $p$ Value \\
\hline TLIF, no. of pts & 22 & 5 & 37 & \\
\hline Change in SL, ${ }^{\circ}$ & $3.5 \pm 6.5$ & $-3.6 \pm 5.5$ & $1.6 \pm 6.0$ & 0.069 \\
\hline LLIF, no. of pts & 14 & 8 & 18 & \\
\hline Change in SL, ${ }^{\circ}$ & $-0.93 \pm 4.03 \dagger$ & $2.2 \pm 5.8 \dagger$ & $4.5 \pm 5.8^{*}$ & 0.002 \\
\hline ALIF, no. of pts & 6 & 4 & 2 & \\
\hline Change in $\mathrm{SL},{ }^{\circ}$ & $7.7 \pm 5.6$ & $10.5 \pm 9.4$ & $11.3 \pm 8.1$ & 0.514 \\
\hline
\end{tabular}

Mean values are presented $\pm S D$. TLIF and LLIF cages had a maximum lordotic cage angle of $15^{\circ}$. The $p$ value reports the type I error rate of the composite test (ANOVA). Pairwise comparisons with Bonferroni corrections reported for the SL changes only.

* Significantly different compared to $10^{\circ}-12^{\circ}$.

† Significantly different compared to $15^{\circ}-20^{\circ}$.

LIFs performed for degenerative pathology found that greater lordotic cage angle was generally not associated with a significantly larger increase in segmental or lumbar lordosis in cages ranging between $6^{\circ}$ and $20^{\circ}$ (Table 4). However, subgroup analyses showed that in LLIF surgery, cages of $15^{\circ}$ were able to generate larger increases in SL compared to $6^{\circ}-8^{\circ}$ and $10^{\circ}-12^{\circ}$ cages, showing that there may be a lordosis-generating effect of hyperlordotic cages in LLIF surgery. Otherwise, the major factors associated with increased SL were use of an anterior approach and an anteriorly positioned cage (Tables 3 and 6). Anterior cage position appeared to be particularly important to achieving SL, as an anteriorly positioned cage was the only independent correlate with SL change in our multivariate linear regression model. To our knowledge, this investigation is the largest series of MIS procedures examining the impact of cage lordotic angle on postoperative SL. Our findings support the following conclusions: 1) the lordosis achieved through TLIF or LLIF techniques likely depends more on anatomical limitations than the cage lordotic angle, and 2) anteriorly positioned cages are mandatory for optimizing lordosis during MIS interbody fusions.

While our findings may appear to contradict recent evidence that the lordotic angle of the TLIF or LLIF cage leads to increased SL gain, ${ }^{23,24}$ a closer look at surgical techniques among published series demonstrates that our findings are in line with past research. Hong et al. compared SL after TLIF with $4^{\circ}, 8^{\circ}$, and $15^{\circ}$ cages, finding a $6.5^{\circ}$ increase in SL in the $15^{\circ}$ cohort, compared to increases of $2.7^{\circ}$ and $3.1^{\circ}$ in the $4^{\circ}$ and $8^{\circ}$ cohorts, respectively. ${ }^{23}$ However, the authors utilized an open approach, with bilateral facetectomies and a subtotal laminectomy. ${ }^{23}$ The addition of bilateral facet resections or posterior column osteotomies has been well established as a key step to increase the SL achieved with interbody fusion., ${ }^{725}$ In contrast, we utilized a paramedian approach through a tubular retractor with a unilateral facetectomy to access the disc space, which is commonly used by surgeons performing minimally invasive TLIF for degenerative pathology. The small increase in SL achieved in our series is in line
TABLE 6. Baseline characteristics and radiographic parameters of patient groups according to cage positioning

\begin{tabular}{lccc}
\hline & \multicolumn{3}{c}{ Cage Position } \\
\cline { 2 - 4 } & Anterior $(n=83)$ & Posterior $(n=33)$ & $p$ Value \\
\hline Preop SL & $14.9 \pm 7.8$ & $14.13 \pm 6.88$ & 0.669 \\
\hline Postop SL & $19.1 \pm 7.0$ & $15.3 \pm 7.8$ & 0.011 \\
\hline Change in SL & $4.2 \pm 6.7$ & $-0.32 \pm 5.3$ & 0.001 \\
\hline
\end{tabular}

Values are presented as degrees. Mean values are presented \pm SD.

with the findings of other investigators who have utilized the same technique. ${ }^{13,26}$ Khechen et al. reviewed a series of 60 patients who underwent MIS TLIF with unilateral facetectomy, finding an average $1^{\circ}$ increase in SL in both the $8^{\circ}$ expandable cage and $5^{\circ}$ static cage cohorts $(\mathrm{p}>0.05){ }^{26}$ Thus, the ability of MIS TLIF to restore lordosis is likely reliant on the anatomical limitations posed by the intact contralateral facet and ALL; structures that increased cage lordosis cannot overcome.

With regard to LLIF, our series found that the lordotic cage angle was associated with SL only once the cage lordotic angle reached $15^{\circ}$. This finding appears to be consistent with prior research. In an investigation consisting of 61 LLIF surgeries, Sembrano et al. compared pre- and postoperative SL in $10^{\circ}$ cage and a nonlordotic cage cohorts, finding that the $10^{\circ}$ cages led to a significant increase of $2.8^{\circ}$ from the preoperative SL $(\mathrm{p}=0.01)$, while the nonlordotic cages increased SL by $0.6^{\circ}(p=0.71){ }^{24}$ While the authors do not comment on whether this difference of $2.4^{\circ}$ was significant between the cohorts, they conclude that lordotic cages elicit a larger change in SL. In contrast, our analysis was designed to explicitly compare the change in SL between lordotic cage angles; furthermore, our minimum cage lordosis in the comparisons was $6^{\circ}$ (as opposed to $0^{\circ}$ ). Accordingly, we found that these small gains in SL were only significant in higher degrees of cage lordosis (average SL change $-0.93^{\circ}, 6^{\circ}-8^{\circ}$ cages; vs $2.2^{\circ}, 10^{\circ}-12^{\circ}$ cages; vs $4.5^{\circ}, 15^{\circ}-20^{\circ}$ cages, $\mathrm{p}=0.002$ ). Other investigations on LLIF using $10^{\circ}$ cages have corroborated an average increase in SL of approximately $2.5^{\circ}$, a range supported by our study. ${ }^{27,28}$ Combining this past research with the findings in this study, the SL change with LLIF surgery appears to be on average one-fourth to one-third of the cage lordotic angle. Thus, the same anatomical limitations that apply to generating lordosis through a TLIF (i.e., intact anterior longitudinal ligament, dependence on resection of posterior elements) also apply to LLIF, creating a "ceiling effect" on how much lordosis the cage lordotic angle is able to induce. ${ }^{8}$ The clinical relevance of these constraints has been borne out in the adult deformity literature, where the limitations of multilevel LLIF without anterior column realignment in restoring lumbar lordosis are well described. ${ }^{6,29,30}$ If surgeons wish to increase lordosis through LLIF or TLIF, they should not rely on an increased cage lordotic angle; rather, they must plan to release the restricting anatomical structures (adjunct steps that can still be performed in an MIS manner) and focus on positioning the cage in the anterior half of the disc space. ${ }^{31}$ 
Likewise, given that ALIF relies on resection of the ALL in order to access the disc space, it is not unexpected that the anterior approach was associated with a larger gain in SL. Interbody implants utilized in ALIF surgery have been historically wedged to mimic the increased anterior height of the vertebral disc at the lower lumbar levels-the relative power of utilizing this approach to restore lower lumbar lordosis is well recognized. ${ }^{13,32}$ Interestingly, the cage lordotic angle did not significantly increase the SL gain within the ALIF cohort. Similar to LLIF, there may be a ceiling effect imparted by the posterior elements, which an increased cage lordotic angle cannot overcome. On the other hand, in a series reporting on ALIF for revision front-back lumbar fusion (during which the posterior structures were released), Kadam et al. reported an increase in SL of approximately one-half the cage value $\left(6.1^{\circ}, 12^{\circ}\right.$ cages; $12.5^{\circ}, 20^{\circ}$ cages; $17.7^{\circ}, 30^{\circ}$ cages $) .^{33}$ Further research will be needed to determine the interplay between cage lordotic angle and resection of posterior elements in ALIF surgery.

Our analysis also found that an anteriorly positioned cage was associated with a larger gain in SL, findings corroborated by previous investigations. ${ }^{12,34}$ Landham et al. quantified bilateral PLIF cage position using a "centre point ratio" (CPR), which represented the ratio of the distance between the posterior vertebral wall and the center of the cage to the length of the inferior endplate. ${ }^{12}$ The investigators reported a strong correlation between the CPR and lordosis gain $(r=0.537, p<0.001)$, but no association with the cage lordotic angle $(\mathrm{p}>0.05)$. In an older PLIF series, Groth and colleagues compared threaded cylindrical cages (TCCs), wedged structural allograft (WSA), and vertical cages (VCs), finding that only the VCs were able to induce SL, which the authors attributed to the anterior or central position of the VC cage. They hypothesized that this design avoided the posterior intervertebral "bony block" created by the other devices, allowing for differential distraction of the disc space. ${ }^{34}$ The fact that our technique differed from these series only speaks more strongly to the need for an anteriorly placed cage. Given that the posterior elements are not resected in the MIS approaches described in our series, placing an anterior cage that can maximize the cantilever arm for posterior compression is essential. While we did not specifically look at the cage footprint in our series, surgeons should consider the tradeoff between a larger footprint to decrease subsidence and the potential for a posterior "bony block" if the cage cannot be placed far enough anteriorly, especially if inducing $\mathrm{SL}$ is a surgical goal.

\section{Study Limitations}

Our investigation was not without limitations. First, certain analyses were likely underpowered to detect statistical differences between the changes in SL. For example, within the ALIF subgroup ( $\mathrm{n}=12$ patients), the SL gain was $7.7^{\circ}$ with $6^{\circ}-8^{\circ}$ cages, $10.5^{\circ}$ with $10^{\circ}-12^{\circ}$ cages, and $11.3^{\circ}$ with $15^{\circ}-20^{\circ}$ cages. A larger series may have shown that these differences in SL were statistically significant. Regardless of this limitation, the absolute differences are highly unlikely to carry any clinically significant consequences in single-level degenerative lumbar cases and may also be within the range of measurement error. Therefore, we maintain that this limitation did not influence the overall conclusion of the study-lordotic cages do not have a statistically or clinically significant role in generating lordosis during MIS interbody fusions for degenerative lumbar pathology. Second, we only measured postoperative radiographs in the early postoperative period (2-6 weeks). This period was purposefully chosen as the timepoint of interest, as the loss of SL with time through cage settling or subsidence has been well demonstrated. ${ }^{23,35}$ We postulated that if there was to be any differential effect induced by the lordotic cage angle, it would be most clearly demonstrated on early postoperative films; as such, we chose the first standing postoperative radiographs as the outcome of interest. Third, it is important to note that no zero-degree cages were included in analyses (Table 1), thus, the conclusions of the study are only applicable to cages between $6^{\circ}$ and $20^{\circ}$. The study was not designed to compare nonlordotic cages to lordotic cages. Last, the role of selection bias on the part of the surgeon must be recognized. The decision-making process that went into utilizing one approach or cage over another was multifactorial and beyond the scope of this paper. However, the findings of this study have supported the clinical equipoise necessary to design a randomized prospective trial comparing lordotic cage configurations.

\section{Conclusions}

In conclusion, our investigation of 116 MIS interbody fusions found that the lordotic cage angle has clinically and statistically insignificant effects in the generation of SL in patients undergoing surgery for degenerative lumbar pathology. Cage lordotic angle may play a greater role in LLIF surgery than in TLIF or ALIF surgery, but this role is still likely to be minimal and only seen at higher cage lordotic angles $\left(>15^{\circ}\right)$. To our knowledge, this study is the largest series of MIS lumbar fusions investigated to analyze the impact of cage lordotic angle on postoperative SL. Surgeons who wish to create large increases in lordosis with MIS interbody fusion should consider resection of the posterior elements or release of the ALL, as there is a ceiling effect to the amount of lordosis that can be generated by the cage alone. Any additional step will have tradeoffs (foraminal height, morbidity of approach, etc.) that must be balanced with the goals of surgery. Furthermore, this study joins previous literature demonstrating that cage position in the anterior half of the disc space is essential to maximizing the SL gain, another factor of which surgeons should be cognizant during MIS interbody fusions. Last, as the number of cage options increases, our findings set the groundwork for future prospective trials that may determine whether the elimination of surgeon selection bias leads to statistical and clinical differences between cage designs.

\section{References}

1. Park P, Fu KM, Mummaneni PV, et al. The impact of age on surgical goals for spinopelvic alignment in minimally invasive surgery for adult spinal deformity. J Neurosurg Spine. 2018;29(5):560-564. 
2. Lafage R, Schwab F, Glassman S, et al. Age-adjusted alignment goals have the potential to reduce PJK. Spine (Phila Pa 1976). 2017;42(17):1275-1282.

3. Carlson BB, Saville P, Dowdell J, et al. Restoration of lumbar lordosis after minimally invasive transforaminal lumbar interbody fusion: a systematic review. Spine J. 2019;19(5): 951-958.

4. Vaishnav AS, Saville P, McAnany S, et al. Retrospective review of immediate restoration of lordosis in single-level minimally invasive transforaminal lumbar interbody fusion: a comparison of static and expandable interbody cages. Oper Neurosurg (Hagerstown). 2020;18(5):518-523.

5. Than KD, Park P, Fu KM, et al. Clinical and radiographic parameters associated with best versus worst clinical outcomes in minimally invasive spinal deformity surgery. $J$ Neurosurg Spine. 2016;25(1):21-25.

6. Haque RM, Mundis GM Jr, Ahmed Y, et al. Comparison of radiographic results after minimally invasive, hybrid, and open surgery for adult spinal deformity: a multicenter study of 184 patients. Neurosurg Focus. 2014;36(5)(E13):E13.

7. Robertson PA, Armstrong WA, Woods DL, Rawlinson JJ. Lordosis recreation in transforaminal and posterior lumbar interbody fusion: a cadaveric study of the influence of surgical bone resection and cage angle. Spine (Phila Pa 1976). 2018;43(22):E1350-E1357.

8. Lovecchio F, Qureshi SA. The current state of minimally invasive approaches to adult spinal deformity. Curr Rev Musculoskelet Med. 2019;12(3):318-327.

9. Skovrlj B, Belton P, Zarzour H, Qureshi SA. Perioperative outcomes in minimally invasive lumbar spine surgery: A systematic review. World J Orthop. 2015;6(11):996-1005.

10. Mok JK, Gang CH, Qureshi S, McAnany SJ. Using minimally invasive techniques adds to the value equation for select patients. J Spine Surg. 2019;5(suppl 1):S101-S107.

11. Mundis GM Jr, Turner JD, Kabirian N, et al. Anterior column realignment has similar results to pedicle subtraction osteotomy in treating adults with sagittal plane deformity. World Neurosurg. 2017;105:249-256.

12. Landham PR, Don AS, Robertson PA. Do position and size matter? An analysis of cage and placement variables for optimum lordosis in PLIF reconstruction. Eur Spine J. 2017; 26(11):2843-2850.

13. Watkins RG IV, Hanna R, Chang D, Watkins RG III. Sagittal alignment after lumbar interbody fusion: comparing anterior, lateral, and transforaminal approaches. J Spinal Disord Tech. 2014;27(5):253-256.

14. Fujii K, Yamazaki M, Kang JD, et al. Discogenic back pain: literature review of definition, diagnosis, and treatment. JBMR Plus. 2019;3(5):e10180.

15. Kumar A, Merrill RK, Overley SC, et al. Radiation exposure in minimally invasive transforaminal lumbar interbody fusion: the effect of the learning curve. Int J Spine Surg. 2019; 13(1):39-45.

16. Vaishnav AS, Merrill RK, Sandhu H, et al. A review of techniques, time demand, radiation exposure, and outcomes of skin-anchored intraoperative 3D navigation in minimally invasive lumbar spinal surgery. Spine (Phila Pa 1976). 2020; 45(8):E465-E476.

17. Virk $S$, Qureshi S. Navigation in minimally invasive spine surgery. J Spine Surg. 2019;5(suppl 1):S25-S30.

18. Overley SC, McAnany SJ, Andelman S, et al. Return to play in adolescent athletes with symptomatic spondylolysis without listhesis: a meta-analysis. Global Spine J. 2018;8(2):190-197.

19. Murray MR, Skovrlj B, Qureshi SA. Surgical treatment of isthmic spondylolisthesis. Clin Spine Surg. 2016;29(1):1-5.

20. Qureshi S, Lu Y, McAnany S, Baird E. Three-dimensional intraoperative imaging modalities in orthopaedic surgery: a narrative review. J Am Acad Orthop Surg. 2014;22(12): 800-809.
21. Harris PA, Taylor R, Minor BL, et al. The REDCap consortium: Building an international community of software platform partners. J Biomed Inform. 2019;95:103208.

22. Lafage R, Ferrero E, Henry JK, et al. Validation of a new computer-assisted tool to measure spino-pelvic parameters. Spine J. 2015;15(12):2493-2502.

23. Hong TH, Cho KJ, Kim YT, et al. Does lordotic angle of cage determine lumbar lordosis in lumbar interbody fusion? Spine (Phila Pa 1976). 2017;42(13):E775-E780.

24. Sembrano JN, Horazdovsky RD, Sharma AK, et al. Do lordotic cages provide better segmental lordosis versus nonlordotic cages in lateral lumbar interbody fusion (LLIF)? Clin Spine Surg. 2017;30(4):E338-E343.

25. Jagannathan J, Sansur CA, Oskouian RJ Jr, et al. Radiographic restoration of lumbar alignment after transforaminal lumbar interbody fusion. Neurosurgery. 2009;64(5):955-964.

26. Khechen B, Haws BE, Patel DV, et al. Static versus expandable devices provide similar clinical outcomes following minimally invasive transforaminal lumbar interbody fusion. HSS J. 2020;16(1):46-53.

27. Acosta FL, Liu J, Slimack N, et al. Changes in coronal and sagittal plane alignment following minimally invasive direct lateral interbody fusion for the treatment of degenerative lumbar disease in adults: a radiographic study. J Neurosurg Spine. 2011;15(1):92-96.

28. Sharma AK, Kepler CK, Girardi FP, et al. Lateral lumbar interbody fusion: clinical and radiographic outcomes at 1 year: a preliminary report. J Spinal Disord Tech. 2011;24(4): 242-250.

29. Anand N, Baron EM, Khandehroo B. Limitations and ceiling effects with circumferential minimally invasive correction techniques for adult scoliosis: analysis of radiological outcomes over a 7-year experience. Neurosurg Focus. 2014; 36(5):E14.

30. Choy W, Miller CA, Chan AK, et al. Evolution of the minimally invasive spinal deformity surgery algorithm: an evidence-based approach to surgical strategies for deformity correction. Neurosurg Clin N Am. 2018;29(3):399-406.

31. Cheung ZB, Chen DH, White SJW, et al. Anterior column realignment in adult spinal deformity: a case report and review of the literature. World Neurosurg. 2019;123:e379-e386.

32. Lee N, Kim KN, Yi S, et al. Comparison of outcomes of anterior, posterior, and transforaminal lumbar interbody fusion surgery at a single lumbar level with degenerative spinal disease. World Neurosurg. 2017;101:216-226.

33. Kadam A, Wigner N, Saville P, Arlet V. Overpowering posterior lumbar instrumentation and fusion with hyperlordotic anterior lumbar interbody cages followed by posterior revision: a preliminary feasibility study. J Neurosurg Spine. 2017; 27(6):650-660.

34. Groth AT, Kuklo TR, Klemme WR, et al. Comparison of sagittal contour and posterior disc height following interbody fusion: threaded cylindrical cages versus structural allograft versus vertical cages. J Spinal Disord Tech. 2005;18(4): 332-336.

35. Salem KMI, Eranki AP, Paquette S, et al. Do intraoperative radiographs predict final lumbar sagittal alignment following single-level transforaminal lumbar interbody fusion? $\mathrm{J} \mathrm{Neu-}$ rosurg Spine. 2018;28(5):486-491.

\section{Disclosures}

Dr. Iyer reports receiving research support from Innovasis, being a member of the scientific advisory board of Healthgrades, and receiving speakers' bureau fees from Globus Medical. Dr. McAnany reports consulting for Medicrea, Medtronic Sofamor Danek USA, NuVasive, Stryker, Titan Spine, and Zimmer Biomet. Dr. Albert reports consulting for NuVasive; being a patent holder for DePuy Synthes Spine and Zimmer Biomet; receiving book 
royalties from Elsevier, JP Medical Publishers, Springer, Thieme Medical Publishers, and Zimmer Biomet; ownership interest in Augmedics, Bonovo Orthopedics, CytoDyn, HS2, Innovative Surgical Designs, InVivo Therapeutics, Morphogenesis, Paradigm Spine, Physician Recommended Nutriceuticals, Precision Orthopedics, Pulse Equity, Spinicity, Strathspey Crown, and Surg.IO; serving as a scientific advisory board member or other office holder of the American Orthopaedic Association, Back Story LLC, and Scoliosis Research Society; and serving on the editorial board of Spine Universe. Dr. Qureshi reports receiving royalties from Globus Medical and Stryker K2M; stock ownership in Avaz Surgical and Vital 5 (past relationship); consulting for Paradigm Spine, Globus Medical, and Stryker K2M; serving as a scientific advisory board member or other office holder for the Association of Bone and Joint Surgeons, Cervical Spine Research Society, Healthgrades, International Society for the Advancement of Spine Surgery, LifeLink.com, Minimally Invasive Spine Study Group, North American Spine Society, Simplify Medical, Society of Minimally Invasive Spine Surgery, and Spinal Simplicity; serving on the editorial board of Annals of Translational Medicine and Contemporary Spine Surgery; receiving honoraria from AMOpportunities and RTI Surgical; and receiving speakers' bureau fees from Globus Medical.

\section{Author Contributions}

Conception and design: all authors. Acquisition of data: all authors. Analysis and interpretation of data: all authors. Drafting the article: all authors. Critically revising the article: all authors.

Reviewed submitted version of manuscript: all authors. Approved the final version of the manuscript on behalf of all authors:

Qureshi. Statistical analysis: all authors. Administrative/technical/ material support: all authors. Study supervision: Qureshi.

\section{Supplemental Information}

\section{Previous Presentations}

These findings were presented at the International Society for the Advancement of Spine Surgery 2019 Annual Meeting, April 5, 2019, Anaheim, CA; and the Lumbar Spine Research Society meeting, April 5, 2019, Chicago, IL.

\section{Correspondence}

Sheeraz Qureshi: Hospital for Special Surgery, New York, NY. sheerazqureshimd@gmail.com. 